\title{
Article
}

\section{Separation of Cations from Nitric Acid Solutions Using Commercially Available Ion Exchange Resins}

Bond, Gary, Eccles, Harry and Emmott, John David

Available at http://clok.uclan.ac.uk/28434/

Bond, Gary ORCID: 0000-0001-5347-2341, Eccles, Harry ORCID: 0000-00021652-3370 and Emmott, John David (2019) Separation of Cations from Nitric Acid Solutions Using Commercially Available Ion Exchange Resins. Journal of Chemical Engineering \& Process Technology, 10 (1). ISSN 2157-7048

It is advisable to refer to the publisher's version if you intend to cite from the work. http://dx.doi.org/10.4172/2157-7048.1000393

For more information about UCLan's research in this area go to http://www.uclan.ac.uk/researchgroups/ and search for <name of research Group>.

For information about Research generally at UCLan please go to http://www.uclan.ac.uk/research/

All outputs in CLoK are protected by Intellectual Property Rights law, including Copyright law. Copyright, IPR and Moral Rights for the works on this site are retained by the individual authors and/or other copyright owners. Terms and conditions for use of this material are defined in the policies page.

\section{CLoK}

Central Lancashire online Knowledge www.clok.uclan.ac.uk

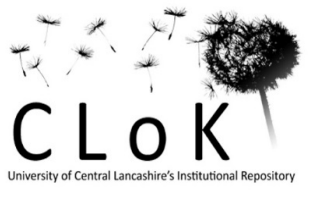




\title{
Separation of Cations from Nitric Acid Solutions Using Commercially Available Ion Exchange Resins
}

Gary Bond, Harry Eccles* and John D Emmott

School of Physical Sciences and Computing, University of Central Lancashire, Preston PR1 2HE, UK

\begin{abstract}
In a previous publication, the authors described a chromatographic process for the selective separation of fission products and minor actinides from uranium and plutonium in nitric acid solution. This paper has evaluated commercially available ion exchange materials for capacity, rate of uptake and selectivity for some fission products (inactive) and cerium (iii) and (iv) as surrogate for $\mathrm{Pu}$ and $\mathrm{U}$. The fission products studied where $\mathrm{Cs}, \mathrm{Sr}$ and $\mathrm{Zr}$ as these for various reasons present major challenges for the existing PUREX process and waste management. The commercial resins evaluated were various sulfonic acid, chelate ion exchangers and an undisclosed inorganic material all supplied by Purolite Ltd.
\end{abstract}

Keywords: Reprocessing; PUREX; Ion chromatographic separation; Cesium; Strontium; Commercial resins

\section{Introduction}

The potential for extractive chromatography as a replacement and/ or complementary reprocessing option to the PUREX process has been previously described [1]. UCLan's process involves the separation of fission products and minor actinides from uranium and plutonium isotopes in 1 to $3 \mathrm{M}$ nitric acid. This paper evaluates the potential of commercially available ion exchangers for the separation of $\mathrm{Sr}$, Cs, Co and $\mathrm{Zr}$ ions from $\mathrm{Ce}$ (iii/iv) ions the surrogates for $\mathrm{Pu}$ and uranium [2]. These fission product cations were selected as:

1. Their chemistries and behaviour are different,

2. They account for a significant amount of $\beta / \gamma$ activity present in spent fuel dissolver liquor,

3. $\mathrm{Zr}$ is responsible for significant challenges in the PUREX process [3].

Cerium ions (iii/iv) have been used as a surrogate for $\mathrm{Pu}$ in a variety of studies ranging from reprocessing, fuel fabrication to waste management [4]. The liquid-liquid extraction of cerium ions from nitrate solution using tri butyl phosphate was well established even before the conception of the PUREX process [5]. The Ce (iv) ion forms relatively weak nitrato complexes in nitric acid solution $(\sim 1 \mathrm{~mole} / \mathrm{l})$, with the $\mathrm{Ce}^{4+}$ ion predominating but with $\mathrm{Ce}\left(\mathrm{NO}_{3}\right)_{3}{ }^{+}$and $\mathrm{Ce}\left(\mathrm{NO}_{3}\right)_{2}{ }^{2+}$ ions increasing in stronger nitric acid [6].

$\mathrm{Xe}, \mathrm{Zr}, \mathrm{Mo}, \mathrm{Nd}, \mathrm{Cs}$ and $\mathrm{Ru}$ isotopes which are formed in the largest amounts in thermal fission, constitute about $70 \%$ of the fission product weight after a cooling time of ten years. Cesium and strontium and daughter isotopes account for about $>90 \%$ of the total activity $(\mathrm{Bq} / \mathrm{t}$ $\mathrm{U}$ ) from fission products for 8-year cooled fuel, with a burn-up of $45 \mathrm{GWd} / \mathrm{t}$ (Table 1). At cooling times 10 to 1,000 years the activities of strontium-90 a strong $\beta$ emitter with a half-life of 28.8 years and caesium-137 with a half-life of 30 years a strong $\beta / \gamma$ emitter dominate among the fission products. They are the two most important fission products when considering reagent stability in a reprocessing flowsheet.

Although the only important oxidation number for zirconium is +4 , the solution chemistry is complicated as a number of ionic species can be present depending on the solution conditions. Zirconium ions can undergo extensive hydrolysis to produce colloidal species and polymerisation, which are $\mathrm{pH}$ and concentration dependent [7].

Although there is an abundance of metal extraction data for the selected commercial ion exchangers most if not all are restricted to slightly acid, neutral to alkaline $\mathrm{pH}$ regions far removed from 1 to 3 $\mathrm{M}$ acid [8]. The influence of $\mathrm{pH}$ (acidity) is known to influence both extraction and separation efficiencies; in addition metal speciation and hydrated ionic radii will be affected $[9,10]$.

UCLan's chromatography process relies on the sequential separation of individual radionuclides or families of radionuclides using appropriate stationary phases. The envisaged process will initially remove the comparative short-lived radionuclides such as $\mathrm{Cs}$ and $\mathrm{Sr}$ isotopes (significant $\beta / \gamma$ emitters) thus reducing the radiation damage to downstream stationary phases (Figure 1) [11]. Reduction in radiation flux will allow organic exchangers to be considered for the subsequent separation of other radionuclides in later stages.

A major, if not the major separation consideration for the stationary phase will be the ability to achieve decontamination values $\left(D_{f}\right)$ comparable, if not better with those attained in the PUREX process for example $10^{7}[12]$. To achieve this figure would require the stationary phase to reduce say the $\mathrm{Cs} / \mathrm{Sr}$ concentration from $\sim 3 \mathrm{~g} / \mathrm{Kg} \mathrm{U}$ to $\sim 0.3$ $\mu \mathrm{g} / \mathrm{Kg} \mathrm{U}$, based on the data in Tables 1 and 2 [8].

The optioneering investigations reported in this paper are based on batch studies to identify candidate exchangers that will be further evaluated in column experiments. Some of the selected commercial ion exchangers exhibit good extraction efficiencies for copper; this metal was included in this study to provide a comparison between their intended commercial use and their performance in 1 to $3 \mathrm{M}$ nitric acid conditions, i.e., benchmarking exercise $[8,13]$.

Extraction efficiencies, separation factors and rate of cation uptake were calculated from equilibrium batch studies over a range of nitric acid molar strengths.

*Corresponding author: Harry Eccles, Department of Nuclear Materials, University of Central Lancashire, Preston PR1 2HE, UK, Tel: 01772893550; E-mail: heccles@uclan.ac.uk

Received November 26, 2018; Accepted March 20, 2019; Published March 25, 2019

Citation: Bond G, Eccles H, Emmott JD (2019) Separation of Cations from Nitric Acid Solutions Using Commercially Available Ion Exchange Resins. J Chem Eng Process Technol 9: 393. doi: 10.4172/2157-7048.1000393

Copyright: (c) 2019 Bond G, et al. This is an open-access article distributed under the terms of the Creative Commons Attribution License, which permits unrestricted use, distribution, and reproduction in any medium, provided the original author and source are credited. 
Citation: Bond G, Eccles H, Emmott JD (2019) Separation of Cations from Nitric Acid Solutions Using Commercially Available lon Exchange Resins. J Chem Eng Process Technol 10: 393. doi: 10.4172/2157-7048.1000393

Page 2 of 10

\begin{tabular}{|c|c|c|c|}
\hline Radioisotope & $\mathrm{Bq} / \mathrm{t} \mathrm{U}$ & Heat rating factor $(\mathrm{W} / \mathrm{Bq})$ & Heat rating contribution (W/tU) \\
\hline Y-90 & $3.14 \mathrm{E}+15$ & $1.50 \mathrm{E}-13$ & $4.70 \mathrm{E}+02$ \\
\hline Sr-90 & $3.14 \mathrm{E}+15$ & $3.13 E-14$ & $9.84 \mathrm{E}+01$ \\
\hline Rh-106 & $8.90 \mathrm{E}+13$ & $2.60 \mathrm{E}-13$ & $2.31 \mathrm{E}+01$ \\
\hline Sb-125 & $4.65 E+13$ & 8.54E-14 & $3.97 \mathrm{E}+00$ \\
\hline Cs-134 & $5.02 E+14$ & $2.75 E-13$ & $1.38 \mathrm{E}+02$ \\
\hline Cs-137 & $4.38 \mathrm{E}+15$ & $2.98 \mathrm{E}-14$ & $1.31 \mathrm{E}+02$ \\
\hline $\mathrm{Ba}-137 \mathrm{~m}$ & $4.14 \mathrm{E}+15$ & $1.06 \mathrm{E}-13$ & $4.39 E+02$ \\
\hline Ce-144 & $3.33 \mathrm{E}+13$ & $1.78 \mathrm{E}-14$ & $5.92 \mathrm{E}-01$ \\
\hline Pr-144 & $3.33 \mathrm{E}+13$ & $1.98 \mathrm{E}-13$ & $6.60 \mathrm{E}+00$ \\
\hline Eu-154 & $1.72 E+14$ & $2.42 \mathrm{E}-13$ & $4.16 \mathrm{E}+01$ \\
\hline Am-241 & $7.65 \mathrm{E}+13$ & $9.04 \mathrm{E}-13$ & $6.91 \mathrm{E}+01$ \\
\hline $\mathrm{Cm}-242$ & $9.93 \mathrm{E}+09$ & $9.95 \mathrm{E}-13$ & $9.88 \mathrm{E}-03$ \\
\hline $\mathrm{Cm}-244$ & $1.21 \mathrm{E}+14$ & $9.46 \mathrm{E}-13$ & $1.14 \mathrm{E}+02$ \\
\hline \multicolumn{3}{|c|}{ Total } & $1.53 E+03$ \\
\hline
\end{tabular}

*Above values for $45 \mathrm{GWd} / \mathrm{t} \mathrm{U}$ burn up and 8-year cooling post reactor.

Table 1: Heat rating factor for some radioisotopes present in spent fuel dissolver liquor*.

\begin{tabular}{|c|c|}
\hline Radionuclide & Approximate concentration \\
\hline$U$ & $\sim 300 \mathrm{~g} / \mathrm{l}$ \\
\hline $\mathrm{Pu}$ & $3.6 \mathrm{~g} / \mathrm{l}$ \\
\hline $\mathrm{Np}$ & $170 \mathrm{mg} / \mathrm{l}$ \\
\hline $\mathrm{Am}$ & $225 \mathrm{mg} / \mathrm{l}$ \\
\hline $\mathrm{Cm}$ & $8 \mathrm{mg} / \mathrm{l}$ \\
\hline Alkali metals $(\mathrm{Cs}, \mathrm{Rb})$ & $1.3 \mathrm{~g} / \mathrm{l}$ \\
\hline Y and lanthanides & $1.05 \mathrm{~g} / \mathrm{l}$ \\
\hline Zr & $4.4 \mathrm{~g} / \mathrm{l}$ \\
\hline Se and Te & $1.5 \mathrm{~g} / \mathrm{l}$ \\
\hline $\mathrm{Mo}$ & $220 \mathrm{mg} / \mathrm{l}$ \\
\hline $\mathrm{Tc}$ & $1.4 \mathrm{~g} / \mathrm{l}$ \\
\hline $\mathrm{Ru}, \mathrm{Rh}, \mathrm{Pd}$ & $350 \mathrm{mg} / \mathrm{l}$ \\
\hline Ag, Cd, Sn. Sb & $1.8 \mathrm{~g} / \mathrm{l}$ \\
\hline
\end{tabular}

${ }^{*}$ Concentrations are based on a typical irradiated PWR $3.7 \%$ U-235 fuel with a burn up of $45 \mathrm{GWd} / \mathrm{t} \mathrm{HM}$, cooled for 3 years

Table 2: Dissolver liquor concentrations*.

\section{Materials and Methods}

\section{Reagents and instrumentation}

Purolite Ltd., provided a variety of resins and adsorbents; their general properties are displayed in Table 3: $500 \mathrm{ppm}$ stock solutions were prepared of Cs, Sr, Ce (III), Ce (IV) Co and Cu nitrate salts in 1\% $\mathrm{NO}_{3}$ - for batch uptake experiments; for the rate of uptake experiments, a $\mathrm{Zr}$ solution of 3,000 ppm in $2 \mathrm{M}$ nitric acid was prepared.

All the reagents were of analar grade quality or equivalent with the exception of nitric acid, which was of trace metal analytical grade. The cation concentrations were determined using Thermo X-Series ICP-MS with Thermo PlasmaLab version 2.5.11.321. The deionised water which had a conductivity of $18.2 \mathrm{M} \Omega . \mathrm{cm}$ used in these experiments was sourced from a Thermo Scientific Barnstead NANOPURE ion exchanger.

All equipment was routine standardised and appropriate standards used, in particular for ICP-MS determinations. Equilibration of cation solutions with the appropriate ion exchanger was accomplished using Julabo SW22 water bath set at the appropriate temperature and agitated at $200 \mathrm{rpm}$.

\section{Batch uptake experiments}

As the acid molar strength of the feed solution will be a determining and possible limiting factor on the separation of ions and efficiency of

\begin{tabular}{|c|c|c|}
\hline Resin Name & Functional Group & Structure \\
\hline $100 \mathrm{H}$ & Sulphonic Acid & Gel Polystyrene with divinylbenzene at 8\% \\
\hline C100X10MBH & Sulphonic Acid & $\begin{array}{c}\text { Gel Polystyrene with divinylbenzene at } \\
10 \%\end{array}$ \\
\hline S910 & Amidoxime & $\begin{array}{c}\text { Polyacryclic crosslinked with } \\
\text { divinylbenzene }\end{array}$ \\
\hline D5530 & Unknown & Unknown \\
\hline
\end{tabular}

Table 3: Adsorbents used and their functionality and polymeric properties.

any chromatographic separation, batch studies of the effect of nitric acid strength (up to $4 \mathrm{M}$ ) on the uptake of ions by all adsorbents were initially investigated. Experiments were carried out in $250 \mathrm{ml}$ Durran bottles with $100 \mathrm{ml}$ of the required concentration of nitric acid; to this, a requisite amount of the cation stock solution was added to bring the cation concentration to $500 \mathrm{ppb} .1 \mathrm{~g}$ of the adsorbent was then added to the bottle, sealed and placed in the water bath and agitated at $25^{\circ} \mathrm{C}$ for 24 hours ( 24 hrs. taken to approximate equilibrium). Percentage uptake values were calculated and plotted against acid strength (Figures 2-4).

Selectivity co-efficient at the same acid concentration were calculated by Equation 1:

$$
S=\frac{\text { Percent uptake of ion } A}{\text { Percent uptake of ion } B}
$$

The amount of each ion adsorbed per $g$ of resin was calculated by Equation 2:

$$
Q_{e}=\frac{\left(C_{o}-C_{e}\right) * V}{m}
$$

Where $\mathrm{C}_{\mathrm{o}}$ is the initial ion concentration $\left(\mathrm{mgl}^{-1}\right), V$ the volume of nitric acid solution $(\mathrm{l}), \mathrm{m}$ the weight of resin $(\mathrm{g})$ and $\mathrm{C}_{\mathrm{e}}$ the concentration at the end of the experiment taken as equilibrium $\left(\mathrm{mgl}^{-1}\right)$.

Distribution coefficients were calculated from Equation 3:

$$
K_{D}=\frac{\left(C_{o}-C_{e}\right) * V}{C_{e} m}
$$

\section{Rate of cation uptake}

Small samples were periodically withdrawn from the 3,000 ppm $\mathrm{Zr} / 2 \mathrm{M}$ nitric acid solution $(100 \mathrm{ml})$ equilibrating at the appropriate temperature and subsequently analysed. It was considered that the $\mathrm{Zr}$ ions had reached equilibrium with exchange materials after 24 hours $\left(C_{\mathrm{e}}\right)$. Rates of $\mathrm{Zr}$ ion uptake as a function of time were calculated either as a percentage of $C_{\mathrm{e}}$ or $\mathrm{Zr}$ mass uptake $(\mathrm{mg} / \mathrm{g})$. 


\section{Results and Discussion}

\section{Capacity and selectivity}

Selectivity and distribution coefficients were determined for six ions on three adsorbents with four ions being tested with the S910. Only one sulphonic acid resin graph is displayed as the similarity between the sulfonic $\mathrm{C} 100 \mathrm{H}$ and $\mathrm{C} 100 \times 10 \mathrm{MBH}$ resins, is differentiated only by the amount of divinyl benzene cross-linking agent within the resin structure (Figure 2). It is appreciated however that the degree of cross-linking does affect both capacity and selectivity of sulphonic acid ion exchange resins but in this study the affect and implications were marginal [14].

Uptake was observed for most of the cations over quite a large nitric acid molar range for the sulfonic resins, with the exception of cesium, the adsorption of which falls off quickly as the acidity is raised above $1.0 \mathrm{M}$.

At this acid concentration, the dissociation of sulphonic acid will be slightly impaired, and as the nitric acid concentration increases, the dissociation of $\mathrm{SO}_{3} \mathrm{H}$ will be further reduced in order to maintain the equilibrium, viz:

$$
\mathrm{R}-\mathrm{SO}_{3} \mathrm{H} \leftrightarrow \mathrm{R}^{-\mathrm{SO}_{3}}+\mathrm{H}^{+} \quad \mathrm{pK}_{\mathrm{a}} \text { of } \sim-2.8 \text { [15] }
$$

$\mathrm{Ce}$ and $\mathrm{Zr}$ ions are capable of overcoming this lack of dissociation by displacing the hydrogen ion attached to the functional group. As the measured maximum uptake for these ions is of the order $50 \mu \mathrm{g} / \mathrm{g}$ this would entail only $10^{-3} \%$ dissociation of the sulphonic acid group for a 1:1 $\mathrm{SO}_{3}-\mathrm{Zr}$ complex. The uptake of ions is higher for the more charged species, so zirconium (IV) is more retained than cerium (IV)>cerium (III) > strontium (II)>copper and cobalt (II)>caesium (I); this sequence is consistent with previously measured selectivities for sulphonic acid resins [16]. Cerium as reported earlier and zirconium ions are capable of forming nitrato- complexes in nitric acid which may assist in the uptake of these ions by the sulphonic acid functional group, in particular for monovalent species such as $\mathrm{Ce}\left(\mathrm{NO}_{3}\right)_{3}{ }^{+}$.

The acid concentrations for $50 \%$ extraction for $\mathrm{Cs}, \mathrm{Co}, \mathrm{Cu}, \mathrm{Sr}, \mathrm{Ce}$ (iii), Ce (iv) and $\mathrm{Zr}$ are $0.15,0.4,0.65,1.40,1.50$ and $2.10 \mathrm{M}$ respectively
(Figure 2). These extraction profiles indicate that an effective separation of $\mathrm{Cs}, \mathrm{Co}, \mathrm{Cu}$ and $\mathrm{Sr}$ ions from $\mathrm{Zr}$ ions could be achieved in $2.0 \mathrm{M}$ nitric acid, but the separation would be less efficient for Ce ions from $\mathrm{Zr}$ ions.

This separation factor trend for sulphonic acid resins is underpinned by the data reported in Tables 4 and 5 . In $2 \mathrm{M}$ acid, the separation factor for Cs ions from $\mathrm{Zr}$ ions is about 29 and nearly 20 and 16.4 for Co and $\mathrm{Sr}$ ions respectively for $\mathrm{C} 100 \mathrm{H}$. The performance of $100 \mathrm{x} \mathrm{MBH}$ is slightly inferior with values of $22, \sim 10$ and 6.5 respectively, which may be due to the higher degree of cross-linking.

The difference in the sulfonic acid distribution coefficients is interesting; although they gave similar shaped graphs, the more highly cross-linked resin gave nearly double the distribution coefficient. This may be due to the interesting chemistry displayed by zirconium speciation at low acid concentrations $\left(\mathrm{ZrO}^{2+}, \mathrm{Zr}^{4+}\right.$ and $\left[\mathrm{Zr}_{4}(\mathrm{OH})_{8}\right.$ $\left.\left.\left(\mathrm{H}_{2} 0\right)_{16}\right]^{8+}\right)$. The variation in charges, hydrated radii and ionic diameters displayed at these low nitric acid concentrations will have a dramatic effect on the adsorption on to the resin. The pore size of the resin, density of active sites on its surface and capacity will all be limiting factors affecting uptake.

Large ions such as the $\left[\mathrm{Zr}_{4}(\mathrm{OH})_{8}\left(\mathrm{H}_{2} \mathrm{O}\right)_{16}\right]^{8+}$ will be less able to penetrate the internal structures and active sites within a resin than that of smaller ion such as $\mathrm{ZrO}^{2+}$ or $\mathrm{Zr}^{4+}$. It will also take more active sites on the resin to adsorb a $8^{+}$charged hydrated ion than that of a $4^{+}$ or $2^{+}$ion. This will effectively reduce the capacity of the resin for $\mathrm{Zr}$. The relatively high cross-linking will reduce pore size within the resin, possibly making it too small for the hydrated ions, thus slowing the uptake. The ion does however behave as expected at the higher acid concentrations of most interest to this project, on both $\mathrm{C} 100$ resins.

The separation performance of the amidoxime resin for $\mathrm{Zr}$ ions from other cations is far superior to the sulphonic acid ion exchangers, for example at $50 \%$ extraction the acid concentrations are 0.1 and $0.2 \mathrm{M}$ for $\mathrm{Zr}$ and $\mathrm{Ce}(\mathrm{iv})$ ions respectively (Figure 3). At these acid concentrations uptake of other cations is below $10 \%$.

The distribution ratios recorded for $\mathrm{Zr}$ ions from 1 to $3 \mathrm{M}$ nitric acid solutions exceed 900 demonstrating the binding capacity of the amidoxime group (Tables 6 and 7).

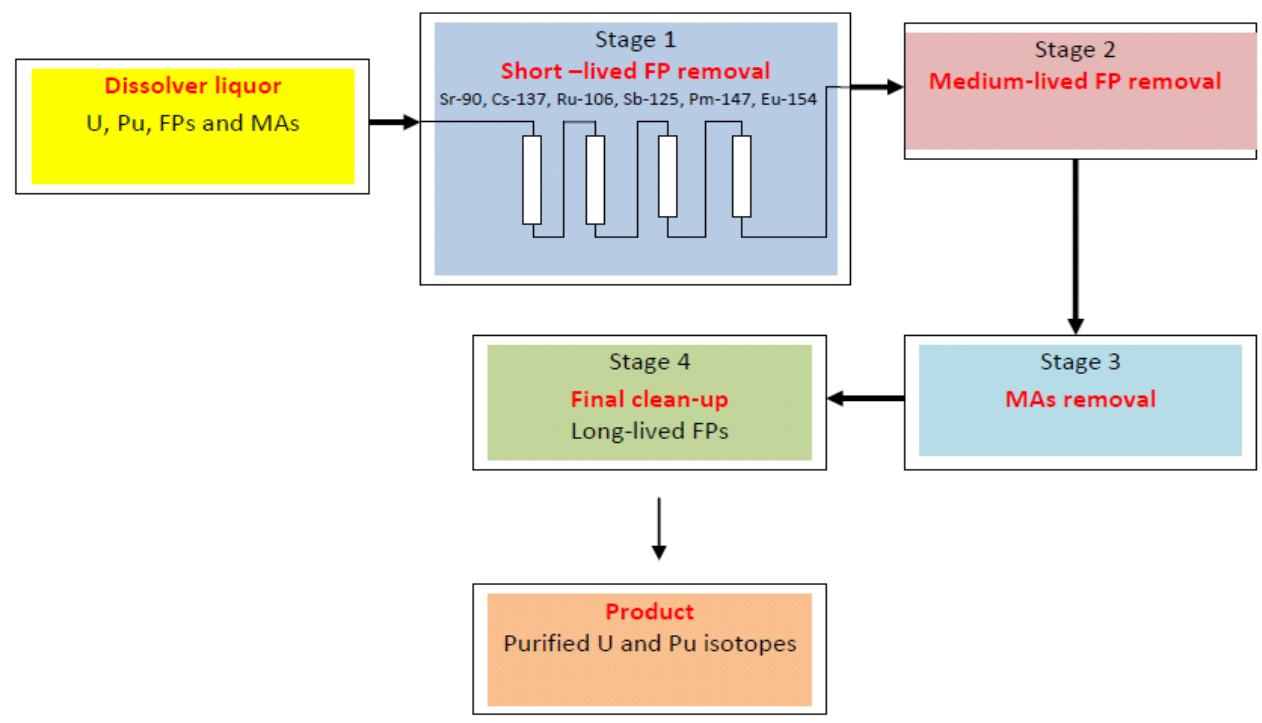

Figure 1: UCLan's Continuous chromatography separation process. 


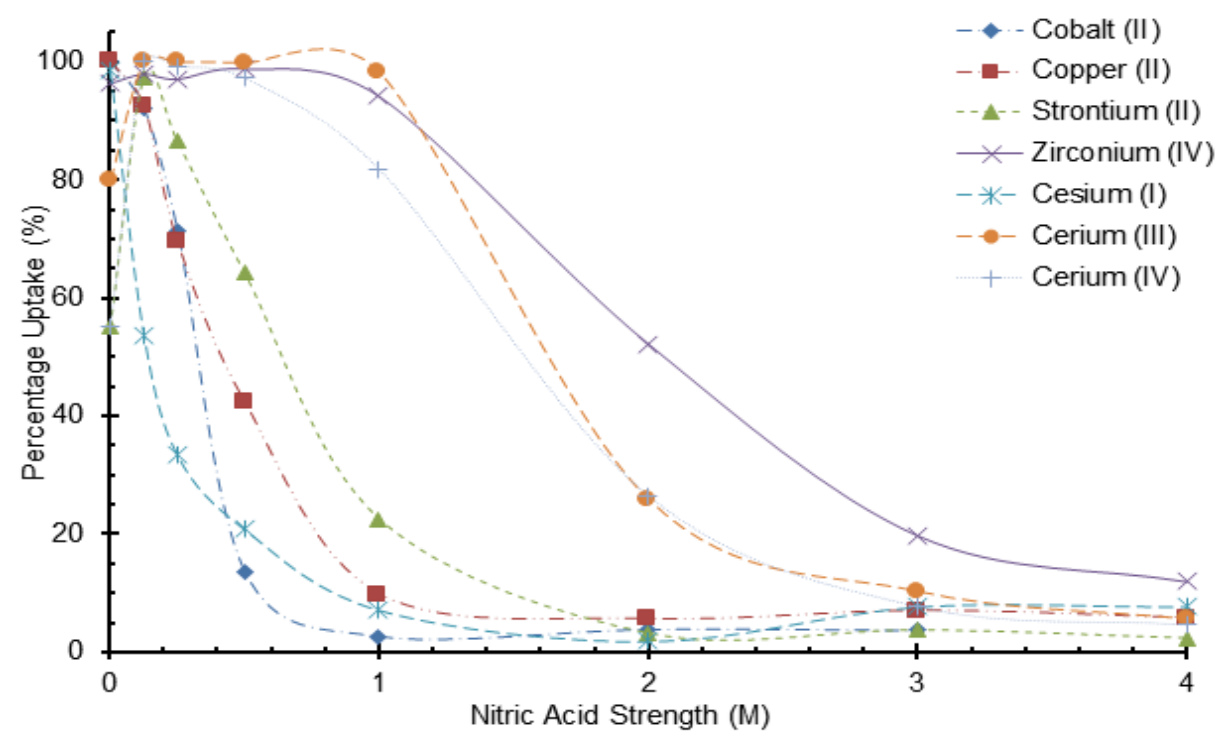

Figure 2: Percentage uptake of various cations in nitric acid on $\mathrm{C} 100 \mathrm{H}$.

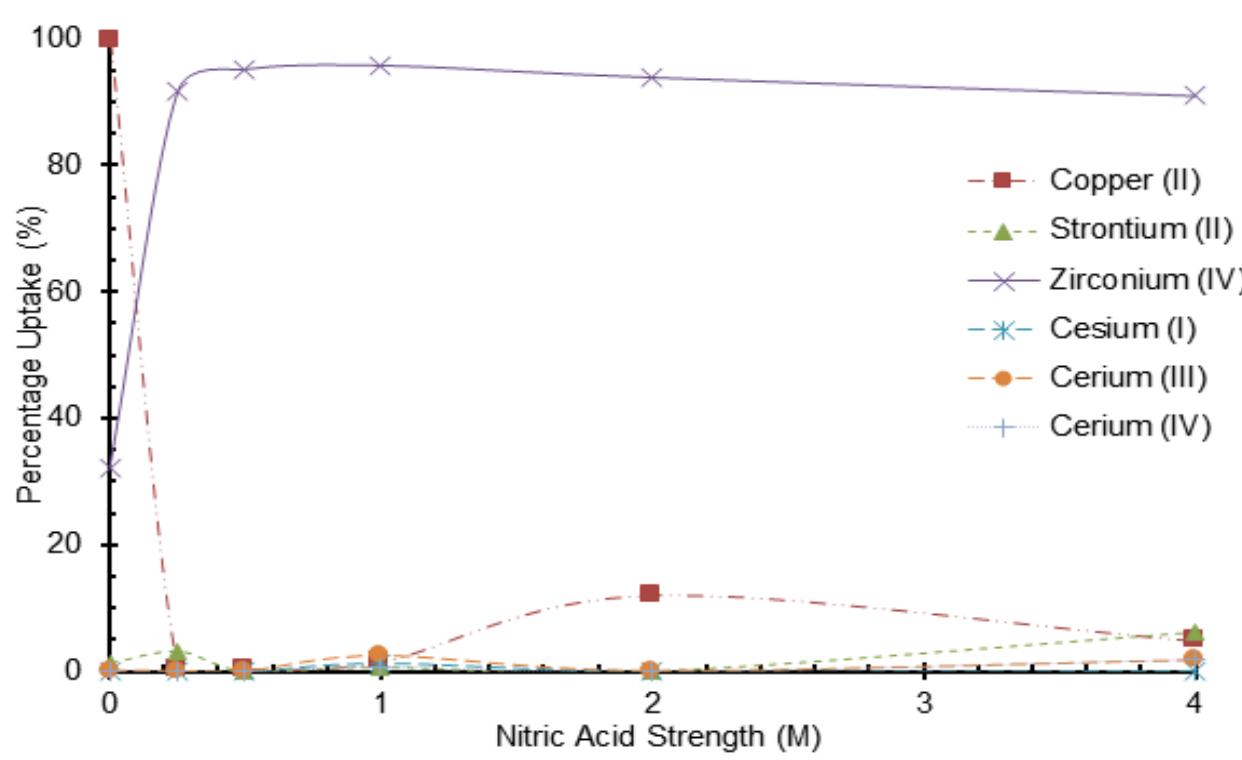

Figure 3: Percentage uptake of various cations in nitric acid on S910.

The reduction in uptake for the sulfonic resins can be described by the equilibrium between hydrogen ions on the resin, those in solution and the cation as previously explained. The $S 910$ being a chelating resin is slightly different, it has the ability to complex with specific ions but reject others. The selectivity can be further enhanced by increasing acidity; this is demonstrated in the experiments where in deionised water the uptake of Ce (IV) ion is greater than that of $\mathrm{Zr}$ ion but is reduced close to zero once $\mathrm{HNO}_{3}$ is above 1 mol.l-1 $[1]$.

In general hydroxamic acids are weak donors with the $\mathrm{pKa}$ values varying from 7.05 (nitrobenzohydroxamic acid) to 11.33 (N-phenyln-butylhydroxamic acid) [17]. amidoxime resins to remove cations from acid solutions has been reported on several previous occasions [18-20]. Vernon studied various transition metals such as $\mathrm{Ni}, \mathrm{Co}, \mathrm{Cu}$,
$\mathrm{Pb} \mathrm{V}, \mathrm{Fe}$ and $\mathrm{U}, \mathrm{Hg}$ and $\mathrm{Au}$ in near neutral to acid solutions ( $\mathrm{pH}$ values 6.0 to 1.0) and reported that $\mathrm{V}$ and $\mathrm{Au}$ had the highest capacities of $0.8 \mathrm{mmoles} / \mathrm{g}$ and $\sim 2.5 \mathrm{mmoles} / \mathrm{g}$ respectively at zero $\mathrm{pH}$ value [21]. The resin also had a high uptake for copper but at $\mathrm{pH}$ value of $6(3.2$ mmoles/g). This high capacity for copper ions is also a characteristic of S910 (40 g/l equivalent to $\sim 0.5$ mmoles/g) [14].

There are extensive reviews of the stability constants and metal complexation properties of hydroxamic acids but with emphasis on benzohydroxamic acid (BHA) complexes [22,23]. The metals of interest to UCLan's chromatographic separation process that have been studied with $\mathrm{BHA}$ and $\mathrm{AHA}$ are $\mathrm{Fe}(\mathrm{iii}), \mathrm{U}(\mathrm{vi}), \mathrm{Ru}(\mathrm{iii}), \mathrm{Zr}$ (iv), $\mathrm{Pu}(\mathrm{vi})$ and rare earths [24].

The stability constants reported in Table 7 were measured in slightly 
Citation: Bond G, Eccles H, Emmott JD (2019) Separation of Cations from Nitric Acid Solutions Using Commercially Available lon Exchange Resins. J Chem Eng Process Technol 10: 393. doi: 10.4172/2157-7048.1000393

Page 5 of 10

Nitric Acid strength

\begin{tabular}{|l|}
\hline \\
\hline \\
\hline \\
\hline \\
\hline \\
\hline \\
\hline \\
\hline \\
\hline
\end{tabular}

(M)

1

1

1

2

2

2

2

2

2

3

3
1

1

3

\begin{tabular}{l|l|l}
3 & $\mathrm{Zr}(\mathrm{IV})$ & 6.17
\end{tabular}

\begin{tabular}{|l|l|l|}
3 & Cs (1) & 2.09 \\
\hline
\end{tabular}

\begin{tabular}{l|l} 
Ce (IV) & 2.88 \\
\hline
\end{tabular}

Ce (III) 2.09
Selective factor

\begin{tabular}{|c|c|c|c|c|c|}
\hline $\mathbf{C u}$ (II) & $\mathbf{S r}$ (II) & $\mathbf{Z r}$ (IV) & $\mathbf{C s}$ (I) & $\mathbf{C e}$ (IV) & $\mathbf{C e}$ (III) \\
\hline 1.46 & 0.54 & 1101 & 2.07 & 104 & 1104 \\
\hline & 0.37 & 1101 & $1 \mathrm{~A} 2$ & 1103 & 0.02 \\
\hline 2.69 & & 1102 & 180 & 1107 & 0.06 \\
\hline 14924 & 55.54 & & 21129 & 4.08 & 160 \\
\hline 1171 & 126 & 0.11 & & 1102 & 102 \\
\hline 3654 & 13.60 & 1124 & $51 / 4$ & & 0.88 \\
\hline 41.49 & $15 \mathrm{~A} 4$ & 1128 & $58 / 4$ & 1.14 & \\
\hline 1146 & 0.83 & 1102 & 1.48 & 0.08 & 1108 \\
\hline & 1.81 & 105 & 123 & 1117 & 117 \\
\hline 0.55 & & 0.03 & 1.79 & 1109 & 109 \\
\hline 18.38 & 3326 & & 59.43 & 114 & 105 \\
\hline 0.31 & 0.56 & 1102 & & 0.05 & 0.05 \\
\hline 5.86 & 10.60 & 132 & 18.95 & & 1197 \\
\hline 613 & 10.92 & 1133 & 19.50 & 1.03 & \\
\hline 1153 & 1.02 & 1116 & 0.48 & 0.35 & 1148 \\
\hline & 1.93 & 1131 & 0.90 & 0.66 & 1190 \\
\hline 0.52 & & 1116 & 0.47 & 1134 & 1147 \\
\hline 327 & 620 & & 2.96 & 2.14 & 2116 \\
\hline 1.11 & 2.13 & 1134 & & 0.72 & 1.00 \\
\hline 1.53 & 2.94 & 1147 & 1.38 & & 1.38 \\
\hline 1.11 & 2.13 & 1134 & 1.00 & 0.72 & \\
\hline
\end{tabular}

\begin{tabular}{|l|l|l|}
\hline Equilibrium coefficient & Distribution coefficient & Retention factor
\end{tabular}

\begin{tabular}{|c|c|c|}
\hline$\left(\mathbf{K}_{\text {ed }}\right)$ & $\left(\mathbf{K}_{\text {ion }}\right)$ & $\begin{array}{c}\text { Ren } \\
\left(\mathbf{K}_{\text {ion }}\right)\end{array}$ \\
\hline 1516 & 0.16 & 1.58 \\
\hline 11172 & 0.11 & 1.08 \\
\hline 2910 & 0.29 & 2.90 \\
\hline 1612.81 & 16.13 & 161.23 \\
\hline 7.57 & 1108 & 1176 \\
\hline 446.84 & 4.47 & 44.81 \\
\hline 39429 & 3.94 & $39 A 8$ \\
\hline 210 & 1103 & 1127 \\
\hline 5.90 & 1106 & 159 \\
\hline 327 & 1103 & 1133 \\
\hline 108.32 & 1.08 & 11192 \\
\hline 1.83 & 0.02 & 1118 \\
\hline 35.38 & 0.71 & $\mathrm{~L} 13$ \\
\hline 34.76 & 0.35 & 3.48 \\
\hline 196 & 0.04 & 0.40 \\
\hline 7.50 & 1108 & 0.75 \\
\hline 3.91 & 1104 & 0.39 \\
\hline 24.40 & 1124 & 245 \\
\hline 2.90 & 1103 & 029 \\
\hline 824 & 108 & 1183 \\
\hline $11 \mathrm{~A} 8$ & 0.12 & 1.15 \\
\hline
\end{tabular}

Table 4: Separation factors and distribution coefficients for $\mathrm{C} 100 \mathrm{H}$.

\begin{tabular}{|c|c|c|c|c|c|c|c|c|c|c|}
\hline \multirow{2}{*}{\multicolumn{2}{|c|}{$\begin{array}{l}\text { Nitric Acid } \\
\text { Strength (M.) }\end{array}$}} & \multicolumn{6}{|c|}{ Selectivity Factor } & \multirow{3}{*}{$\begin{array}{c}\text { Equilibrium Coefficient } \\
\qquad\left(\mathbf{K}_{\mathrm{d}}\right)\end{array}$} & \multirow{3}{*}{$\begin{array}{c}\begin{array}{c}\text { Ditribution Ratio } \\
\left(\mathbf{K}_{\mathrm{ion}}\right)\end{array} \\
0.26\end{array}$} & \multirow{3}{*}{$\begin{array}{c}\begin{array}{c}\text { Retention } \\
\text { Factor }\left(\mathrm{K}_{\mathrm{ion}}\right)\end{array} \\
2.58\end{array}$} \\
\hline & & \multirow{2}{*}{$\begin{array}{c}\text { Co (II) } \\
-\end{array}$} & \multirow{2}{*}{$\begin{array}{c}\mathrm{Cu} \text { (II) } \\
1.04\end{array}$} & \multirow{2}{*}{$\begin{array}{c}\text { Sr (II) } \\
0.35\end{array}$} & \multirow{2}{*}{$\begin{array}{c}\mathrm{Zr} \text { (IV) } \\
01.01\end{array}$} & \multirow{2}{*}{$\begin{array}{c}\text { Cs (I) } \\
1.57\end{array}$} & \multirow{2}{*}{$\begin{array}{c}\mathrm{Ce} \text { (IV) } \\
0.02\end{array}$} & & & \\
\hline 1 & Co (II) & & & & & & & & & \\
\hline 1 & $\mathrm{Cu}$ (II) & 0.96 & - & 0.34 & 0.01 & 1.51 & 0.02 & 24.58 & 0.73 & 2.47 \\
\hline 1 & $\mathrm{Sr}$ (II) & 2.83 & 2.95 & - & 0.02 & 4.46 & 0.06 & 72.61 & 29.46 & 7.30 \\
\hline 1 & $\mathrm{Zr}(\mathrm{IV})$ & 114.36 & 119.37 & 40.42 & - & 180.09 & 2.26 & 2946.42 & 0.16 & 1.64 \\
\hline 1 & Cs (I) & 0.63 & 0.66 & 0.22 & 0.01 & - & 0.01 & 16.30 & 4.49 & 44.81 \\
\hline 1 & $\mathrm{Ce}(\mathrm{IV})$ & 50.51 & 5213 & 17.85 & 0.44 & 79.55 & - & 448.54 & 12.99 & 30.15 \\
\hline 2 & Co (II) & - & 010 & 0.64 & 0.03 & 1.39 & 0.07 & 8.48 & 0.09 & 0.85 \\
\hline 2 & $\mathrm{Cu}$ (II) & 1.43 & - & 0.91 & 0.04 & 1.98 & 0.11 & 12.09 & 0.12 & 122 \\
\hline 2 & $\operatorname{Sr}(I I)$ & 1.56 & 1.09 & - & 0.04 & 2.16 & 0.12 & 1320 & 0.13 & 1.33 \\
\hline 2 & $\mathrm{Zr}(\mathrm{IV})$ & 3971 & 27.82 & 25.45 & - & 55.07 & 2.95 & 33624 & 3.36 & 3319 \\
\hline 2 & Cs (I) & 0.72 & 0.51 & 0.46 & 0.02 & - & 0.05 & 1135.81 & 11.36 & 113.85 \\
\hline 2 & $\mathrm{Ce}(\mathrm{IV})$ & 13.48 & 9.44 & 8.64 & 0.34 & 18.69 & - & 12.63 & 2.45 & 24.70 \\
\hline 3 & Co (II) & - & 0.55 & $\infty$ & 0.01 & 0.29 & 0.03 & 0.73 & 0.01 & 0.07 \\
\hline 3 & $\mathrm{Cu}$ (II) & 1.81 & - & $\infty$ & 0.02 & 0.52 & 0.06 & 1.32 & 0.01 & 0.13 \\
\hline 3 & $\mathrm{Sr}$ (II) & 0.00 & 0.00 & & 0.00 & 0.00 & 57.54 & 0.00 & 0.00 & 0.00 \\
\hline 3 & $\mathrm{Zr}(\mathrm{IV})$ & 78.40 & 43.43 & $\infty$ & - & 2217 & 2.74 & 57.54 & 0.58 & 516 \\
\hline 3 & Cs (I) & 3.44 & 1.91 & $\infty$ & 0.104 & - & 0.12 & 2.49 & 0.03 & 025 \\
\hline 3 & $\mathrm{Ce}(\mathrm{IV})$ & 28.63 & 15.86 & $\infty$ & 0.37 & 8.31 & - & 26.14 & 0.26 & 2.63 \\
\hline
\end{tabular}

Table 5 Separation factors and distribution coefficients for C100X10MBH.

acid to modest alkaline $\mathrm{pH}$ conditions i.e., $~ 2$ to 10 unlike the nitric acid conditions employed in this study. Below $\mathrm{pH}$ values 1.0, the proportion of metal hydoxamate in solution will be small. This for most cations in our study is confirmed by the extraction-acid profiles in Figure 3, the exception is $\mathrm{Zr}$ ions. These profiles and the data in Table 7 would suggest that only mono-dentate or at worst bi-dentate ligands are formed.

The most interesting commercially available material supplied by Purolite Ltd., was D5530 that had strong uptake of cations from 1 to 3
$\mathrm{M}$ nitric acid (Figure 4). In $2 \mathrm{M}$, acid $\mathrm{Zr}$ ion was adsorbed totally with $\mathrm{Cs}, \mathrm{Sr}$, and Ce cations in the $60 \%$ region. At a higher acidity of $4 \mathrm{M}$ the separation was enhanced with $\mathrm{Zr}$ ion still at $100 \%$ uptake but the other cations with the exception of Cs reduced to around $20 \%$ uptake. Unfortunately an explanation of this trend cannot be provided, as the functionality of the material has not been disclosed.

The largest distribution coefficients for $\mathrm{Zr}$ ions were demonstrated by both the amidoxime chelate resin S910 and the inorganic D5530 
Citation: Bond G, Eccles H, Emmott JD (2019) Separation of Cations from Nitric Acid Solutions Using Commercially Available lon Exchange Resins. J Chem Eng Process Technol 10: 393. doi: 10.4172/2157-7048.1000393

Page 6 of 10

\begin{tabular}{|c|c|c|c|c|c|c|c|c|c|c|}
\hline \multirow{2}{*}{$\begin{array}{l}\text { Nitric Acid } \\
\text { Strength (M) }\end{array}$} & \multicolumn{7}{|c|}{ Selectivity Factor } & \multirow[t]{2}{*}{$\begin{array}{c}\text { Equilibrium } \\
\text { Coefficient }\left(K_{d}\right)\end{array}$} & \multirow[t]{2}{*}{$\begin{array}{c}\text { Distribution } \\
\text { Ratio }\left(\mathrm{K}_{\text {ion }}\right)\end{array}$} & \multirow[t]{2}{*}{$\begin{array}{l}\text { Retention } \\
\text { Factor }\left(\mathbf{k}_{\text {ion }}\right)\end{array}$} \\
\hline & & Co (II) & $\mathrm{Sr}(\mathrm{II})$ & $\mathrm{Zr}(\mathrm{IV})$ & Cs (I) & Ce (IV) & $\mathrm{Ce}(\mathrm{III})$ & & & \\
\hline 1 & Co (II) & & 2.55 & 0.00 & 1.30 & 164 & 2.06 & 4.50 & 0.09 & 0.47 \\
\hline 1 & $\mathrm{Sr}(\mathrm{II})$ & 0.39 & & 0.00 & 0.51 & 25 & 0.81 & 0.64 & 0.01 & 0.06 \\
\hline 1 & $\mathrm{Zr}(\mathrm{IV})$ & 1401.30 & 3571.12 & & 1818.06 & 89129 & 2880.01 & 2258.14 & 22.58 & 226.22 \\
\hline 1 & Cs (I) & 0.77 & 1.96 & 0.00 & & 0.49 & 1.58 & 1.25 & 0.01 & 0.13 \\
\hline 1 & Ce (IV) & 1.57 & 4.01 & 0.00 & 2.04 & & 3.23 & & 0.01 & 0.08 \\
\hline 1 & Ce (III) & 0.49 & 1.24 & 0.00 & 0.63 & 131 & & 2.53 & 0.03 & 0.25 \\
\hline 2 & Co (II) & & $\infty$ & 0.01 & $\infty$ & $\infty$ & $\infty$ & 12.32 & 0.25 & 1.26 \\
\hline 2 & $\mathrm{Sr}(\mathrm{II})$ & 0.00 & & 0.00 & $\infty$ & $\infty$ & $\infty$ & 0.00 & 0.00 & 0.00 \\
\hline 2 & $\mathrm{Zr}(\mathrm{IV})$ & 111.65 & $\infty$ & & $\infty$ & $\infty$ & $\infty$ & 153162 & 15.31 & 153.40 \\
\hline 2 & Cs (I) & 0.00 & $\infty$ & 111.65 & & $\infty$ & $\infty$ & 0.00 & 0.00 & 0.00 \\
\hline 2 & Ce (IV) & 0.00 & $\infty$ & 0.00 & $\infty$ & & $\infty$ & 3.70 & 0.07 & 0.75 \\
\hline 2 & Ce (III) & 0.00 & $\infty$ & 0.00 & $\infty$ & $\infty$ & & 4.44 & 0.00 & 0.00 \\
\hline 3 & Co (II) & & 0.76 & 0.01 & 72.92 & 2.83 & 2.71 & 31.29 & 0.63 & 3.16 \\
\hline 3 & $\mathrm{Sr}(\mathrm{II})$ & 1.31 & & 0.01 & 95.82 & 313 & 3.56 & 4155 & 0.81 & 4.11 \\
\hline 3 & $\mathrm{Zr}(\mathrm{IV})$ & 196.73 & 149.72 & & 14346.70 & 557.73 & 533.18 & 962.00 & 19.24 & 99.05 \\
\hline 3 & $\mathrm{Cs}(\mathrm{I})$ & 0.01 & 0.01 & 0.00 & & 0.014 & 0.04 & 1.89 & 0.04 & 0.19 \\
\hline 3 & Ce (IV) & 0.35 & 0.27 & 0.00 & 2512 & & 0.96 & 5.50 & 0.11 & 0.56 \\
\hline 3 & Ce (III) & 0.37 & 0.28 & 0.00 & 26.91 & 1.05 & & 0.96 & 0.02 & 0.10 \\
\hline
\end{tabular}

Table 6: Separation factors and distribution coefficients for S910.

\begin{tabular}{|c|c|c|c|c|c|c|}
\hline Cations & Hydroxamic Acid & $\log \beta 1$ & $\log \beta 2$ & $\log \beta 3$ & $\log \beta 4$ & Reference \\
\hline $\mathrm{U}(\mathrm{vi})$ & $\mathrm{BHA}$ & 8.72 & 16.77 & & & \\
\hline $\mathrm{U}(\mathrm{iv})$ & $\mathrm{BHA}$ & 9.89 & 18.0 & & 32.94 & Barocas [22] \\
\hline $\mathrm{Pu}$ (iv) & $\mathrm{BHA}$ & 12.73 & & 26.32 & & Barocas [22] \\
\hline $\mathrm{Zr}$ (iv) & $\mathrm{BHA}$ & 12.43 & 24.08 & & & Baroncelli [21] \\
\hline $\mathrm{Fe}$ (iii) & $\mathrm{AHA}$ & 11.42 & 21.10 & 28.33 & & Anderegg [23] \\
\hline $\mathrm{Fe}(\mathrm{iii})$ & $\mathrm{BHA}$ & 12.18 & & & & Baroncelli [21] \\
\hline $\mathrm{Ce}$ (iii) & $\mathrm{AHA}$ & 5.45 & 9.79 & 12.8 & & Anderegg [23] \\
\hline La(iii) & $\mathrm{AHA}$ & 5.16 & 9.33 & 11.88 & & Anderegg [23] \\
\hline
\end{tabular}

Table 7: Stability constants for certain cations with $\mathrm{BHA}$ and $\mathrm{AHA}$.

(functionality not disclosed) (Table 8). The distribution coefficient is lower or remains similar as the nitric acid concentration increases for all ions tested, with the exception of Zr on the D5530 adsorbent. Some of the cation's unpredictable uptake with varying acid concentration could be due to the formation of cation-nitrato complexes as already described for $\mathrm{Ce}$ and $\mathrm{Zr}$ ions; this could be equally true for the transition metals $\mathrm{Cu}$ and $\mathrm{Co}$ (Figure 4). This complex formation will also affect ion hydration influencing hydration size. A third contributory factor could be the potential for protonation of the D5530 functional group thus transforming the cation properties to anionic but this would require nitrato complexes of the type $\mathrm{M}\left(\mathrm{NO}_{3}\right)_{5}$. The latter is pure speculation as the precise nature, i.e., functional group of D5530 has not been declared. It would certainly be a challenge to configure a chromatographic separation process in a nitrate/nitric acid with D5530.

\section{Rate of cation uptake}

Understanding the kinetics of exchange of an ion exchange material in separation technology, helps in identifying the reaction pathway and rate dependence on the limiting reacting systems. These rates and mechanisms are influenced by for example ion exchange conditions, nature of the exchanger and exchanging ionic species. Ion exchange kinetics involves the diffusion of metal ions through the solution to the surface and through the particle pores of the resin followed generally by the chemical exchange between functional hydrogen ions and metal ions at the exchanging sites and the diffusion of the displaced ions out of the interior and surface of resin into the solution. Both film and particle diffusion mechanisms are prevalent in ion exchange process, although normally the slowest step (rate-limiting step) for a given system controls the speed of ion exchange.

The equilibration rate of four selected exchangers was studied using $\mathrm{Zr}$ (iv) ions only as it is the only cation to display any significant uptake on each of the adsorbents evaluated in nitric acid conditions.

The rate factor in ion-exchange adsorption is recognized for its importance for the economic and industrial employment of ionexchange resins, no more so than the application under consideration. The kinetic data reported in Figures 5-7, show all four resins increased $\mathrm{Zr}$ ion uptake with time reaching near $100 \%$ after several hours for most resins but with the amidoxime resin having a more rapid uptake initially. At the $300 \mathrm{~min}$. time interval the amidoxime (S910) is the more superior resin with the other three having similar rates. This is unexpected as S910 is a chelating resin and it would be expected that formation of complexes would be slower than simple salt formation, as would be expected with sulphonic acid resins. This irregular behaviour may be due to either the resin porosities being affected differently when in contact with $2 \mathrm{M}$ nitric acid and/or the sulphonic acid resins forming more complex binding to the $\mathrm{Zr}^{4+}$ ions than a simple salt formation, i.e., the incorporation of nitrate ion to achieve electron neutrality.

The largest increase in the uptake rate observed over the temperature range 25 to $45^{\circ} \mathrm{C}$ is for that of the inorganic D5530 whilst the $\mathrm{S} 910$ resin is the least affected by the change in temperature. This however may be due to the capacity of the resin for the ion and the 
Citation: Bond G, Eccles H, Emmott JD (2019) Separation of Cations from Nitric Acid Solutions Using Commercially Available lon Exchange Resins. J Chem Eng Process Technol 10: 393. doi: 10.4172/2157-7048.1000393

Page 7 of 10

initial ion concentration of the liquor driving a concentration gradient effect: essentially meaning that temperature is not the most important factor in the uptake of the $\mathrm{Zr}$ ion for the amidoxime resin. However, this is not borne out when compared to the uptake on the inorganic D5530, which has a similar uptake, which shows a distinct increase in uptake as temperature is increased. At temperatures greater than $45^{\circ} \mathrm{C}$ for both the amidoxime and inorganic exchanger, the $\mathrm{Zr}$ ion uptake values decreased. This could be attributed to the oxidation/degradation of the functional groups. The stability of these four resins is addressed in the next paper of this series.

The difference in the two sulfonic resins is less pronounced than that of the D5530, but does still display a slight increase with temperature.

The increase in uptake rate and capacity with the increase in the temperature of the system is well described in many articles and is expected for both the sulfonic acid resin and amidoxime [25,26].

The increase in uptake related to the temperature increase may be due to the exchange reaction, i.e., being endothermic. Additionally the increase in temperature might cause the electrostatic reactions to become weaker and subsequently the ions to become smaller with a decreased ion solvency within the $\mathrm{HNO}_{3}$ liquor and an increase in the diffusion coefficients through both the film coating the bead and through the resin make up. This will in turn produce a higher exchange velocity between the solution and the resin [27].

In order to elucidate the mechanisms taking place, the degree of extraction $[\ln (1-\alpha)]$ of $\mathrm{Zr}$ ions from solution was plotted against time to derive the rate constant; where $\alpha$ is defined as:

$$
\frac{C_{o}-C_{t}}{C_{o}-C_{e}}=\alpha
$$

Where: $\mathrm{C}_{\mathrm{o}}$ is the initial concentration of metal ion in solution $(\mathrm{mg} / \mathrm{l}), \mathrm{C}_{\mathrm{t}}$ is the concentration of metal ion in solution at any time, $\mathrm{t}$ $(\mathrm{mg} / \mathrm{l}), \mathrm{C}_{\mathrm{e}}$ is the concentration of the metal ion at equilibrium $(\mathrm{mg} / \mathrm{l})$, and $\alpha$ is the fractional attainment of equilibrium of metal ion.
The rate constant $k$ can be derived from:

$$
\ln (1-\alpha)=-k \mathrm{t}
$$

and the activation energy E $a$ calculated using:

$\ln \mathrm{k}=\ln \mathrm{A}-\frac{E_{a}}{R T}$

Where, $\mathrm{A}$ is the pre exponential factor, $\mathrm{R}$ is the gas constant, and $\mathrm{T}$ is temperature.

The plots of $\ln (1-\alpha)$ versus time (not shown) at different temperatures were linear confirming that the ion exchange process is particle diffusion controlled. The value of the overall rate constant, $\mathrm{k}$ was deduced from the slope of the plots. This was substantiated by comparing the coefficient of determination $\left(\mathrm{R}^{2}\right)$ measurements from the $\ln (1-\alpha)$ and $\ln \left(1-\alpha^{2}\right)$ plots for the Vermeulen particle and film diffusion models (Equations 7 and 8 ).

$$
\begin{aligned}
& -\ln \left(1-\alpha^{2}\right)=t \frac{D_{p} \pi^{2}}{r_{p}^{2}} \\
& -\ln (1-\alpha)=t \frac{3 D_{f} C_{o}}{r_{p} \delta C_{e}}
\end{aligned}
$$

Where, $\mathrm{D}_{\mathrm{p}}$ is the diffusion coefficient in the ion exchanger $\left(\mathrm{m}^{2} / \mathrm{sec}\right)$, $r$ is the radius of the particle $(m), D_{f}$ is the diffusion coefficient in the film $\left(\mathrm{m}^{2} / \mathrm{sec}\right)$, Co and Ce are concentrations in the solution and in the exchanger respectively $\left(\mathrm{mol} / \mathrm{m}^{3}\right), \delta$ is the film thickness.

Although coefficient of determination values from the two plots at $25^{\circ} \mathrm{C}$ for the four exchange materials studied were close (more so for the sulphonic acid resins) suggesting an interplay of film and particle diffusion in the exchange process the best fits for all four were with the Vermeulen's particle diffusion model which exhibited higher values of coefficient determination (Table 8).

These values indicate that the rate controlling mechanism for the exchange reaction is particle diffusion. The activation energy values

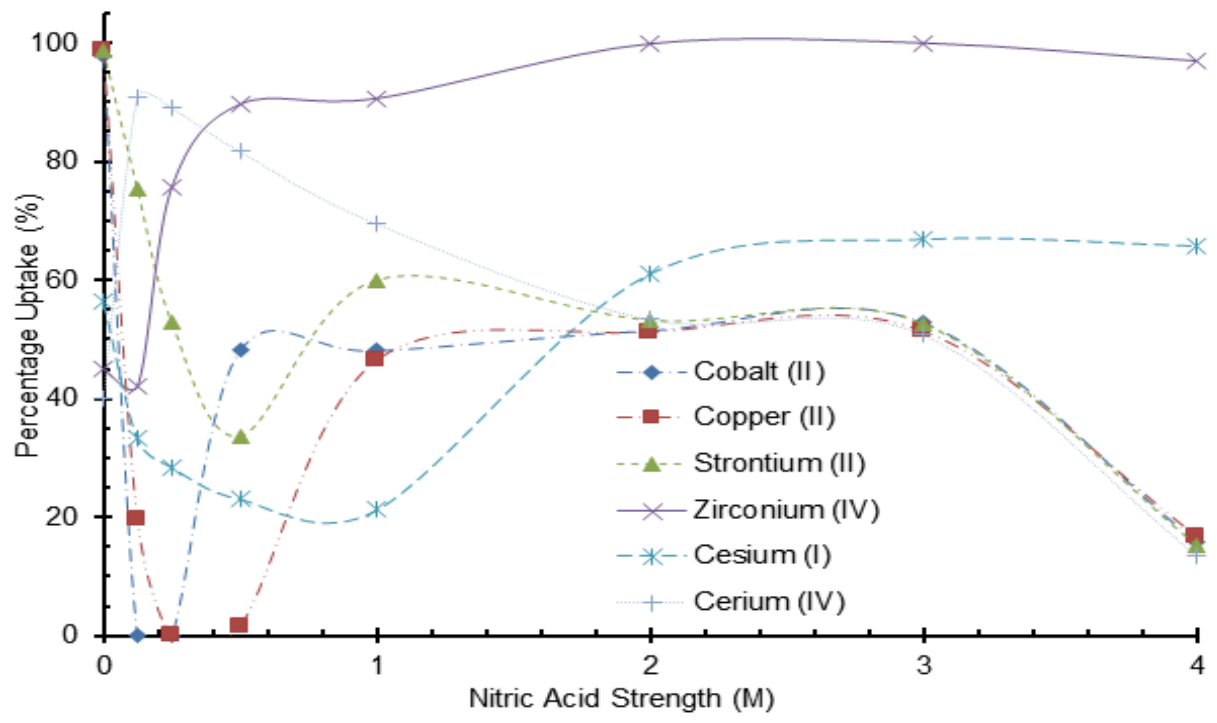

Figure 4: Percentage uptake of various cations in nitric acid on D5530. 
Citation: Bond G, Eccles H, Emmott JD (2019) Separation of Cations from Nitric Acid Solutions Using Commercially Available lon Exchange Resins. J Chem Eng Process Technol 10: 393. doi: 10.4172/2157-7048.1000393

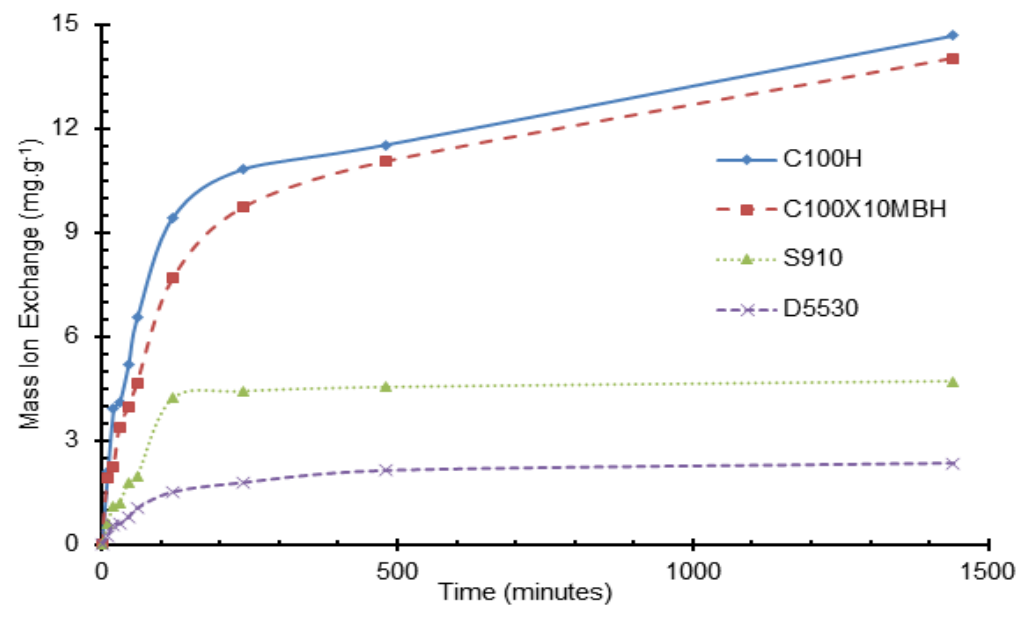

Figure 5: Mass uptake of $\mathrm{Zr}$ (iv) on four adsorbents and resins at $25^{\circ} \mathrm{C}$.

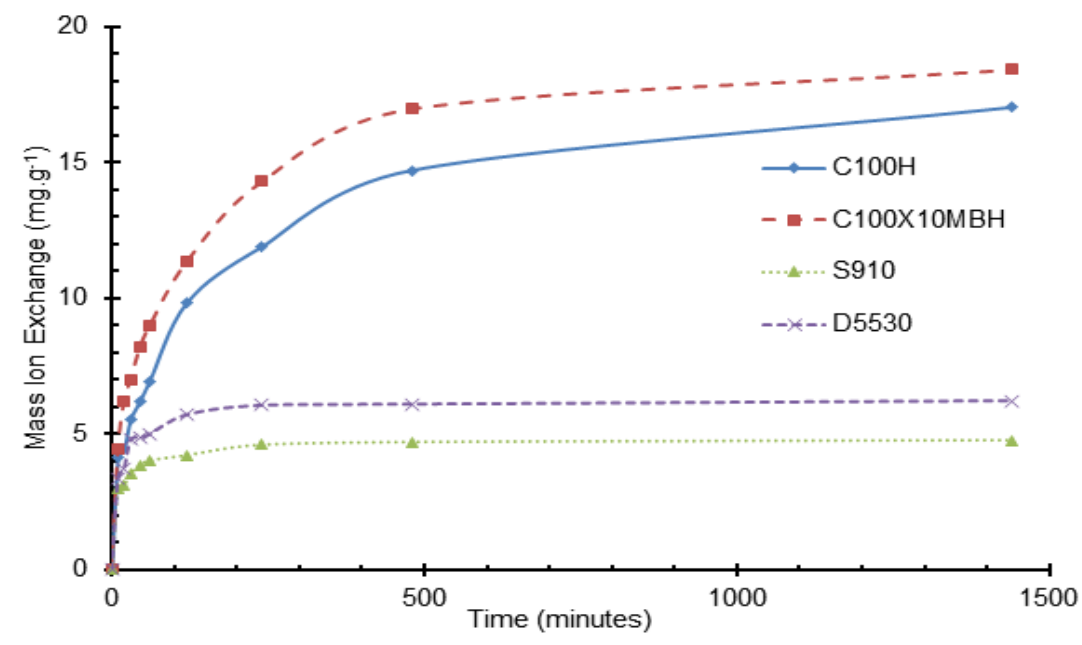

Figure 6: Mass uptake of $\mathrm{Zr}$ (iv) on four adsorbents and resins at $45^{\circ} \mathrm{C}$.

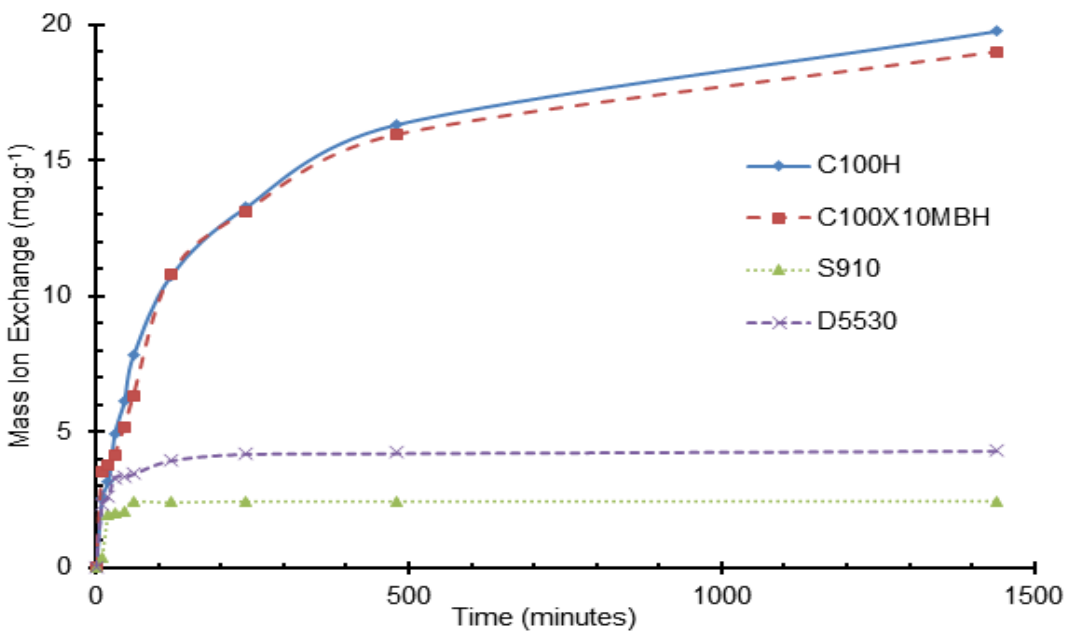

Figure 7: Mass uptake of $\mathrm{Zr}$ (iv) on four adsorbents and resins at $65^{\circ} \mathrm{C}$. 
Citation: Bond G, Eccles H, Emmott JD (2019) Separation of Cations from Nitric Acid Solutions Using Commercially Available lon Exchange Resins. J Chem Eng Process Technol 10: 393. doi: 10.4172/2157-7048.1000393

Page 9 of 10

\begin{tabular}{|c|c|c|c|c|c|c|c|c|c|c|}
\hline \multirow{2}{*}{$\begin{array}{l}\text { Nitric Acid } \\
\text { Strength } \\
\text { (M) }\end{array}$} & \multicolumn{7}{|c|}{ Selectivity Factor } & \multirow[b]{2}{*}{ Equilibrium Coefficient $\left(K_{d}\right)$} & \multirow[b]{2}{*}{ Distribution Ratio ( $\left.\mathrm{K}_{\text {ion }}\right)$} & \multirow[b]{2}{*}{ Retention Factor $\left(\mathrm{K}_{\mathrm{ion}}\right)$} \\
\hline & & Co (II) & Sr (II) & $\operatorname{Zr}(\mathrm{IV})$ & Cs (I) & $\mathrm{Ce}$ (IV) & & & & \\
\hline 1 & Co (II) & - & 1.07 & 0.62 & 0.1 & 3.44 & 1041 & 90.64 & 1.81 & 18.56 \\
\hline 1 & $\mathrm{Cu}(\mathrm{II})$ & 0.93 & - & 0.58 & 0.09 & 3.22 & 0.38 & 84.41 & 1.69 & 17.34 \\
\hline 1 & $\mathrm{Sr}(\mathrm{II})$ & 1.62 & 1.73 & - & 0.15 & 5.57 & 0.66 & 148.3 & 2.97 & 30.03 \\
\hline 1 & $\mathrm{Zr}(\mathrm{IV})$ & 10.48 & 11.21 & 6.47 & - & 36.1 & 4.26 & 955.2 & 19.1 & 194.4 \\
\hline 1 & Cs (I) & 0.29 & 0.31 & 0.18 & 0.03 & - & 0.12 & 155.6 & 3.11 & 31.34 \\
\hline 1 & $\mathrm{Ce}(\mathrm{IV})$ & 2.46 & 2.63 & 1.52 & 0.23 & 8.47 & - & 78.52 & 0.79 & 7.87 \\
\hline 2 & Co (II) & - & 1.02 & 0.94 & 0.00 & 0.68 & 0.93 & 104.9 & 2.1 & 21.26 \\
\hline 2 & $\mathrm{Cu}$ (II) & 0.98 & - & 0.92 & 0.00 & 0.67 & 0.91 & 103.8 & 2.08 & 20.92 \\
\hline 2 & $\operatorname{Sr}(I I)$ & 1.07 & 1.09 & - & 0.00 & 0.73 & 0.99 & 117.7 & 2.35 & 23.63 \\
\hline 2 & $\mathrm{Zr}(\mathrm{IV})$ & 854.2 & 868.3 & 798.9 & - & 580 & 792.77 & 93737 & 1875 & 18920 \\
\hline 2 & Cs (I) & 1.47 & 1.5 & 1.38 & 0.00 & - & 1.37 & 201.2 & 4.02 & 40.37 \\
\hline 2 & $\mathrm{Ce}$ (IV) & 1.08 & 1.1 & 1.01 & 0.00 & 0.73 & - & 94.56 & 1.89 & 19.05 \\
\hline
\end{tabular}

Table 8: Separation factors and distribution coefficients for D5530.

\begin{tabular}{|c|c|c|c|c|c|c|}
\hline \multirow{3}{*}{$\begin{array}{c}\text { Temperature }\left({ }^{\circ} \mathrm{C}\right) \\
\text { Resin }\end{array}$} & \multicolumn{6}{|c|}{$\mathrm{Zr}$ (IV) lon Exchange Capacity $\left(\mathrm{mgg}^{-1}\right)$} \\
\hline & \multicolumn{2}{|c|}{25} & \multicolumn{2}{|c|}{45} & \multicolumn{2}{|c|}{60} \\
\hline & & $+/-$ & & $+/-$ & & $+/-$ \\
\hline $\mathrm{C} 100 \mathrm{H}$ & 14.6 & 0 & 17 & 0.4 & 19.8 & 0.9 \\
\hline $\mathrm{C} 100 \times 10 \mathrm{MBH}$ & 14.0 & 1.3 & 18.4 & 1.7 & 19.0 & 0 \\
\hline SN10 & 4.7 & 1.7 & 4.6 & 0.6 & 2.4 & 0.7 \\
\hline D5530 & 2.4 & 1.2 & 6.1 & 0.5 & 4.2 & 0.2 \\
\hline
\end{tabular}

Table 9: Mass of Zr ion uptake on different adsorbents at differing temperatures.

\begin{tabular}{|c|c|c|c|c|}
\hline \multirow{2}{*}{ Equation } & \multicolumn{4}{|c|}{ Ion exchange material coefficients of determination } \\
\cline { 2 - 5 } & $\mathbf{C 1 0 0 H}$ & $\mathbf{C 1 0 0 \times 1 0 M B H}$ & $\mathbf{S 9 1 0}$ & D5530 \\
\hline$-\ln (1-\alpha)^{2}$ & 0.9914 & 0.9917 & 0.9827 & 0.9482 \\
\hline$-\ln (1-\alpha)$ & 0.9426 & 0.9769 & 0.8777 & 0.9385 \\
\hline
\end{tabular}

Table 10: Comparison of coefficients of determination $\left(R^{2}\right)$ for the Vermeulen particle and diffusion models for $\mathrm{Zr}$ ions at $25^{\circ} \mathrm{C}$

predicted using equation 6 are 20.25, 20.87, 18.25 and $18.02 \mathrm{~kJ} / \mathrm{mole}$ for $\mathrm{C} 100 \mathrm{H}, \mathrm{C} 100 \mathrm{X} 10 \mathrm{MBH}, \mathrm{S} 910$ and D5530 respectively. These values suggest that the mechanism is one of ion exchange of the $\mathrm{Zr}$ ions with hydrogen ions on the sulphonic acid exchange materials, but for D5530 physisorption could also be playing a part and complexation for the S910 (Tables 9 and 10).

\section{Conclusions}

Of the four ion exchange materials reported in this paper the sulphonic acid resins offer little opportunity for chromatographic separation of Cs and/or Sr from other fission products when in nitric acid solutions of 1 to $3 \mathrm{M}$ concentration. The data reported suggest it is the converse, i.e., $\mathrm{Zr}$ could be extracted from these two fission products with either the sulphonic acid resins or the amidoxime resin.

The rate of extraction of $\mathrm{Zr}$ ions from $2 \mathrm{M}$ nitric acid solution is modest i.e., less than $24 \mathrm{hrs}$ to attain equilibrium for the sulphonic acid resins, much quicker for the amidoxime resin.

There was an indication that the exchange materials under investigation in nitric acid solutions at ambient temperature could be undergoing oxidative/hydrolytic damage which was exacerbated at higher temperatures. The stability of these materials is the subject of another paper.
The kinetic data confirms that the rate controlling uptake step for $\mathrm{Zr}$ ions is particle diffusion and the mechanism is one of ion exchange for all four materials, the predicted Ea values were similar $(\sim 20 \mathrm{~kJ} /$ mole). The inorganic exchanger (D5530) had the lowest Ea value (18.02 $\mathrm{kJ} / \mathrm{mole}$ ) which infers that ion exchange could be supplemented by physisorption; with complexation dominating the mechanism for the amidoxime resin (S910).

The separation factors recorded for the four materials were sufficiently encouraging for column studies and chromatographic separations to be undertaken. This is the subject of further publications.

\section{Acknowledgements}

The authors would like to thank Purolite Ltd (Unit D, Llantrisant Business Park, Llantrisant, Rhondda Cynon Taff, Wales, United Kingdom CF72 8LF) for the provision of ion exchange materials and technical support and to the NNL (National Nuclear Laboratory, Central Laboratory, Sellafield, Seascale, Cumbria CA20 1PG), for technical contributions. JDE's Ind CASE award was funded by both the NNL and EPSRC (EP 1501312/1), the authors are grateful for this support.

\section{References}

1. Eccles H, Emmott JD, Bond G (2017) Advanced Reprocessing-The Potential for Continuous Chromatographic Separations. J Chromatogr Sep Tech 8: 348.

2. Law JD, Herbst RS, Rodriguez AM (1995) CMP Flowsheet Development for the Separation of Actinides from ICPP Sodium Bearing Waste using Centrifugal Contactors INEL 95/0414. Nucl Sci Tech 26: 3.

3. Lopez C, Deschanels X, Bart JM, Jollivet P, Denauwer C (1996) Structural study of plutonium surrogates in nuclear glasses. Ceramic Transactions 72 399-408.

4. Warf JC (1949) Extraction of Cerium (iv) nitrate by Butyl Phosphate. J Am Chem Soc 71: 3257-3258.

5. Bayulken S, Sarac AS (1996) Distribution of Ce (iv) species in HNO3-HCLO4 Media and Determination of Stability Constants of the Nitrato Complexes. Tr J Chem 20: 111-117.

6. Blazheva IV, Fedorov YS, Zilberman BY, Mashirov LG (2008) Extraction of Zirconium with Tributyl Phosphate from Nitric acid Solutions. Radiochemistry 50: 256-260.

7. Steinberg EP (1960) The Radiochemistry of Zirconium and Hafnium. NAS-NS Nuclear Science Series.

8. Helfferich F (1962) lon Exchange. McGraw Hill, New York, USA

9. Torapava N (2011) Hydration, Solvation and Hydrolysis of Multicharged Metal lons.

10. Bond G, Eccles H (2013) Continuous Chromatographic Separation of Fission Products and Minor Actinides from Irradiated Nuclear Fuel. UK Patent.

11. Nuclear Science (NEA/NSC/WPFC/DOC) (2012) 15 Spent nuclear fue reprocessing flowsheet. 
Citation: Bond G, Eccles H, Emmott JD (2019) Separation of Cations from Nitric Acid Solutions Using Commercially Available lon Exchange Resins. J Chem Eng Process Technol 10: 393. doi: 10.4172/2157-7048.1000393

Page 10 of 10

12. Puorlite Product Information (2013) Available from: www.purolite.com

13. Streat M, Cloete FLD (1987) lon Exchange of Separation Process Technology. In: Ronald WR (ed.). John Wiley \& Sons, NY, USA.

14. Hamer WJ, Pinching GD, Acree SF (1943) pH values of acid. salt mixtures of some aromatic sulfonic acids at various temperatures and a criterion of completeness of dissociation. Journal of Research of the National Bureau of Standards, p: 31.

15. Bonner OD, Smith LL (1957) A Selectivity Scale for Some Divalent Cations on Dowex 50. J Phys Chem 61: 326-329.

16. Chatterjee B (1978) Donor Properties of Hydroxamic Acids. Coord Chem Rev 26: $281-303$.

17. Taylor RJ, Dennis IS (1990) Hydroxamic Acids-Novel reagents for Advanced Purex Processes. Research and Technology, BNFL Sellafield, Seascale, UK, pp: $2-15$

18. Lin W, Kung S, Dai S (2014) Development of Novel Sorbents for Uranium Extraction from Seawater. NEUP, pp: 11-3151.

19. May I, Taylor RJ, Brown G (1998) The Formation of Hydrophilic Np (iv) Complexes and their Potential Application in Nuclear Fuel Reprocessing. J Alloys Compounds 650: 271-273.

20. Vernon F (1982) Chelating Ion Exchangers-The Synthesis and Uses of Poly (Hydroxamic Acid) Resins. Pure Appl Chem 54: 2151-2158.
21. Baroncelli F, Grossi G (1965) The Complexing Power of Hydroxamic Acids and its Effect on Behavior of Organic Extractants in the Reprocessing of Irradiated Fuels: I. The Complexes between Benzohydroxamic Acid and $\mathrm{Zr}, \mathrm{Fe}$ (III), and $\mathrm{U}$ (VI). J Inorg Nucl Chem 27: 1085-1092.

22. Barocas A, Baroncelli F, Biondi GB, Grossi G (1966) The Complexing Power of Hydroxamic Acids and Its Effect on Behavior of Organic Extractants in the Reprocessing of Irradiated Fuels, II. The Complexes between Benzohydroxamic Acid and Th, U (IV) and Pu (IV). J Inorg Nucl Chem 28: 2961-2967.

23. Anderegg G, Eplatternier FL, Schwarzenbach G (1963) Hydroxamartkomplexes II. Die Anwendung der pH-Methods. Helv Chim Acta 46: 1400.

24. Dizge N, Keskinler B, Barlas H (2009) Sorption of Ni (II) ions from aqueous solution by Lewatit cation-exchange resin. Journal of Hazardous Materials 167 915-926.

25. Mendes MFD (2004) Selective Sorption of Nickel and Cobalt from Sulfate Solutions Using Chelating Resins. International Journal of Mineral Processing 74: 359-371.

26. Alvarez S, Ferrer X, Sarmiento C, Fernandez N, Garcia C (1996) Analysis of Operational Variables in Ion Exchange Kinetics of Cadmium with Synthetic Resins. Ciencia 4: 125-140.

27. Al-Rashed SM, Al-Gaid AA (2012) Kinetic and Thermodynamic Studies on the Adsorption Behavior of Rhodamine B dye on Duolite C-20 Resin. Journal of Saudi Chemistry 16: 209-215. 